\title{
INFLUÊNCIA DO LASER DE CO 2 E DE COMPOSTOS FLUORETADOS NO CONTROLE DA LESÃO DE CÁRIE EM ESMALTE DE DENTE DECÍDUO DESMINERALIZADO - ANÁLISE IN VITRO DA MICRODUREZA SUBSUPERFICIAL
}

\author{
Dissertação apresentada à Faculdade de \\ Odontologia de Ribeirão Preto da \\ Universidade de São Paulo, para obtenção \\ do título de Mestre em Ciências. \\ Programa: Odontopediatria \\ Área de Concentração: Odontopediatria.
}

Orientadora: Profa. Dra. SILMARA APARECIDA MILORI CORONA 
Autorizo a reprodução e divulgação total ou parcial deste trabalho, por qualquer meio convencional ou eletrônico, para fins de estudo e pesquisa, desde que citada a fonte.

FICHA CATALOGRÁFICA

Valério, Rodrigo Alexandre

Influência do laser de $\mathrm{CO}_{2}$ e de compostos fluoretados no controle da lesão de cárie em esmalte de dente decíduo desmineralizado - análise in vitro da microdureza subsuperficial. Ribeirão Preto, 2011.

44p.: il, $30 \mathrm{~cm}$.

Dissertação de Mestrado, apresentada à Faculdade de Odontologia de Ribeirão Preto da Universidade de São Paulo. Área de concentração: Odontopediatria.

Orientadora: Corona, Silmara Aparecida Milori

1. Lasers de $\mathrm{CO}_{2}$. 2. Dente decíduo. 3. Cárie dentária.

4. Fluoretos tópicos. 5. Desmineralização. 6. Dureza. 


\section{FOLHA DE APROVAÇÃo}

VALÉRIO, RA. INFLUÊNCIA DO LASER DE $\mathrm{CO}_{2}$ E DE COMPOSTOS FLUORETADOS NO CONTROLE DA LESÃO DE CÁRIE EM ESMALTE DE DENTE DECÍDUO DESMINERALIZADO ANÁLISE IN VITRO DA MICRODUREZA SUBSUPERFICIAL.

Dissertação apresentada à Faculdade de Odontologia de Ribeirão Preto da Universidade de São Paulo para a obtenção do Título de Mestre em Ciências. Programa: Odontopediatria. Área de concentração: Odontopediatria.

Aprovado em:

1

\section{Banca Examinadora}

Prof. Dr.

Instituição:

Julgamento:

Assinatura:

Prof. Dr.

Instituição:

Julgamento:

Assinatura:

Prof. Dr.

Instituição:

Julgamento:

Assinatura: 


\section{DAdOS CURRICULARES}

\section{RODRIGO ALEXANDRE VALÉRIO}

Nascimento

Filiação

$1996-1999$

1998-1999

2000-2001

2005-2006

2005-2007

$2009-2011$
04 de agosto de 1978 - Taquaritinga/SP

Walter João Valério

Vera Lucia Aparecida Gibertoni Valério

Curso de Graduação Universidade de Marília - UNIMAR

Aperfeiçoamento em Prático de Terceiros Molares Retidos Centro Bauruense de Estudos Odontológicos Bauru/SP

Especialização em Dentística Restauradora Associação Odontológica de Ribeirão Preto - AORP

Curso de Atualização de Implante - Módulo Teórico e Prático Ortotrauma Araraquara/SP

Especialização em Acupuntura Sistêmica Instituto Paulista de Estudos Sistêmicos Ribeirão Preto/SP

Curso de Pós-graduação (Mestrado) em Odontologia Área de Concentração: Odontopediatria Faculdade de Odontologia de Ribeirão Preto - USP 


\section{Dedico este TRABalho,}

Aos meus queridos pais, Walter JoÃo Valério (in memorian) e Vera lucia Aparecida Gibertoni VALÉRIO, pelo amor e apoio incondicionais, sonhos compartilhados, suporte emocional nos momentos difíceis e pelo incentivo constante às minhas escolhas, além de estarem presentes em todos os momentos importantes da minha vida. Serei eternamente grato a vocês pela amável e incansável dedicação.

A meu irmão Walter Valério Neto, minha cunhada Vanessa Cristina Miranda Valério, meu sobrinho João Pedro Miranda Valério, minha tia Cesira lodila Valério, meu primo Frederico Gustavo Valério, meus avós Walter Valério (in memorian), Irma Micali Valério, Hércules Gibertoni (in memorian), Maria Rosa Bernadel Gibertoni (in memorian), por me ensinarem a viver de forma simples e humilde como eram eles, e por transmitirem-me as mais valiosas lições de caráter, amor ao próximo, fé e caridade.

À minha orientadora Professora Doutora Silmara Aparecida Milori Corona por ser um exemplo de dignidade e honestidade num mundo que perdeu o seu valor. Admiro-te como pessoa, por sua alegria, inteligência e por ser uma mãe exemplar.

Plante seu jardim e decore sua alma, ao invés de esperar que alguém Ihe traga flores. E você aprende que realmente pode suportar, que realmente é forte, e que pode ir muito mais longe depois de pensar que não se pode mais. E que realmente a vida tem valor e que você tem valor diante da vida! Nossas dádivas são traidoras e nos fazem perder o bem que poderíamos conquistar, se não fosse o medo de tentar. 


\section{AGRADECI MENTOS ESPECI AIS}

\section{A DEUS:}

Não percas a tua fé entre as sombras do mundo. Ainda que os teus pés estejam sangrando, segue para frente, erguendo-se por luz celeste, acima de ti mesmo. Crê e trabalha. Esforçate no bem e espera com paciência. Tudo passa e tudo se renova na terra, mas o que vem do céu permanecerá. De todos os infelizes os mais desditosos são os que perderam a confiança em Deus e em si mesmo, porque o maior infortúnio é sofrer a privação da fé e prosseguir vivendo. Eleva, pois, o teu olhar e caminha. Luta e serve. Aprende e adianta-te. Brilha a alvorada além da noite. Hoje, é possível que a tempestade te amarfanhe o coração e te atormente o ideal, aguilhoando-te com a aflição ou ameaçando-te com a morte. Não te esqueças, porém, de que amanhã será outro dia.

FRANCISO CÂNDIDO XAVIER

Aos meus pais Walter João Valério e Vera lucia Aparecida Gibertoni Valério:

Pai é uma pena que você não esteja aqui nesse momento pra vivenciar mais uma vitória na minha carreira. Você nos deixou tão cedo! A cada dia que passa sentimos mais sua falta, a saudade aumenta, o coração fica apertado. Mas onde quer que esteja saiba que eu te amo e tenho certeza que esta olhando por todos nós. Muito obrigado por me ensinar a ser uma pessoa humilde, educada e a dar valor nas pequenas coisas da vida. Obrigado por acreditar em mim e no meu potencial, quando outros não o fizeram.

Mãe, a vida já nos pregou tantas peças, enfrentamos tantas situações difíceis, mas graças a Deus conseguimos superar todas. Agradeço-te pela pessoa que você é, sempre amorosa, preocupada, prestativa e infinitamente simples, humilde e devota a Deus. Graças as suas orações e a imensurável bondade que tem no coração, você foi mais que uma mãe, foi também o pai que perdi tão cedo. Obrigado por tudo.

Ao meu irmão Walter Valério Neto, pela sua extrema bondade e pureza no coração. Você é uma pessoa especial na minha vida. Agradeço-te por tudo do fundo do meu coração. 
À minha orientadora Professora Doutora Silmara Aparecida Milori Corona:

Agradeço a Deus todos os dias por ter colocado pessoas tão boas no meu caminho. Você certamente é uma delas. Tu és uma pessoa especial; alegre, inteligente, paciente e prestativa. Agradeço-te por me ter como filho e por fazer parte da minha vida.

\section{Professora Doutora MaRia CRIStina Borsatto:}

Nenhuma palavra pode expressar a gratidão que sinto por você. Obrigado pela confiança depositada, bondade e honestidade. Estou aqui hoje graças a você, e agradeço-lhe infinitamente por isso. Que sua alegria continue contagiando a todos que estão ao seu redor.

Ao Professor Doutor João Neudenir Ariol Filho, pela ajuda prestada desde o início da minha carreira, obrigado pelos ensinamentos, conselhos e por estar sempre ao meu lado nos momentos que precisei.

Ao Professor Doutor FábIo LoURenço Romano, meu muito obrigado pelas orientações e por ensinar-me um pouco de ortodontia. Você é um dos grandes amigos que tenho na Faculdade de Odontologia de Ribeirão Preto. Conte comigo sempre.

Ao Professor Doutor Francisco Wanderley Garcia de Paula e Silva, obrigado pela paciência e por todas as lições. Você é extremamente inteligente. Agradeço por ter desfrutado de todos seus conhecimentos.

Ao Professor Doutor Paulo Nelson Filho, obrigado pela confiança, espero que tenha correspondido as suas expectativas. Admiro-te como pessoa e pesquisador. Guardarei seus ensinamentos por toda a vida.

À Professora Doutora Mônica Campos Serra que sempre esteve disponível a ajudar. Sua inteligência e competência são fontes de inspiração para mim! Obrigado!

À Professora Doutora Raquel Assed BezerRA DA Silva, pela amizade e atenção. Agradeço pelos ensinamentos compartilhados e por sua disposição em ajudar. Obrigado. 
À Professora Doutora AleXandra Mussolino de QueIroz, pelos ensinamentos transmitidos e a confiança depositada na clínica de odontopediatria. Obrigado pelas orientações e elogios.

À Professora Doutora Kranya Victória Díaz Serrano, pela sua alegria, gentileza, compreensão e estímulo. Obrigado por compartilhar comigo seu valioso conhecimento profissional e pela grande amizade que encontrei em você.

À Professora Doutora Aldevina CAmpos de FreitAs, pela dedicação, paciência e amor à profissão.

À minha amiga Marta Maria Martins Giamatel Contente, que teve grande papel nessa conquista, estando sempre disposta a me auxiliar quando necessário. Você é extremamente bondosa, correta e inteligente, com um futuro brilhante pela frente. Espero retribuir essa ajuda, obrigado.

Às amigas Carolina Paes Torres e Jaciara Miranda Gomes da Silva, obrigado pela amizade, companheirismo e ajuda imprescindível em todas as fases deste trabalho. A admiração e o carinho ficarão guardados para sempre. Que Deus ilumine sempre vossos caminhos.

Ao amigo RodRIGo Galo por sua alegria e ajuda intensa. Obrigado pela disposição e companheirismo durante todo esse tempo.

Ao amigo Jeronimo Manço de Oliveira Neto, grande irmão, obrigado por fazer parte dessa conquista. Sempre pronto a colaborar em todos os momentos. Agradeço a Deus por encontrar mais um amigo. Aguardo a oportunidade para retribuir todo esse apoio.

À Cristiane Tomaz Rocha, obrigado por estar ao meu lado durante todo o período laboratorial desse trabalho, ajudando-me, esclarecendo minhas dúvidas, e colaborando para que tudo ficasse perfeito. Agradeço muito por isso. Conte sempre comigo. 
Aos meus amigos de infância: Gustavo Gibertoni, Gustavo Roberto Basilio, Renato Donato Haggy e Ricardo luís Pinto da Cunha por todos os momentos agradáveis vivenciados. Que nossa amizade dure para sempre. Todos vocês contribuíram muito para que eu me tornasse uma pessoa melhor. Obrigado por sempre estarem ao meu lado tanto nos momentos difíceis enfrentados, quanto nas alegrias compartilhadas.

Aos meus amigos: Rogério tadeu Posca, Bruno Benatti, Daniel Ricardo Basilio, Prilyana de barros basso basillo, luciano Eduardo Rosa, Priscila miscossi, lilian abud anselmo, pela amizade, compreensão e toda ajuda prestada.

Aos meus amigos da graduação: Bruno, Caio, Danilo, Kleber, Lélis, luCAS, Luís Henrique, MAURício e Victor, por todos os bons momentos compartilhados.

À amiga Fátıma Rızólı. Você é mais uma pessoa especial que Deus colocou no meu caminho. Sempre alegre, verdadeira e prestativa. Obrigado pela ajuda e conselhos.

Aos amigos Marcelo lourenço da Silva e Josie Resende Torres da Silva, pela amizade e confiança depositada. Obrigado por fazerem parte da minha vida e pelos conhecimentos transmitidos durante o curso de acupuntura.

À amiga Michel Cristina Leite Rovanholo, por toda a ajuda, paciência e alegria partilhadas durante esses dois anos. Você é uma pessoa especial que vou guardar no meu coração para sempre. Obrigado. 


\section{AgRADECI MENTOS}

À Faculdade de Odontologia de Ribeirão Preto da Universidade de São Paulo, na pessoa do atual Diretor Professor Doutor Osvaldo LuIz Bezzon e Vice-Diretor Professor Doutor VALDEMAR Mallet da Rocha BarRos.

À Comissão de Pós-Graduação da Faculdade de Odontologia de Ribeirão Preto da Universidade de São Paulo, na pessoa da atual Presidente Professora Doutora LÉA Assed BezerRA dA Silva, também coordenadora do curso de Pós-Graduação em Odontopediatria. Agradeço pelo determinismo em conseguir a excelência e o reconhecimento deste curso.

Às funcionárias da seção de Pós-Graduação da Faculdade de Odontologia de Ribeirão Preto da Universidade de São Paulo, Isabel Cristina Galino Sola e Regiane Cristina Moi Sacilotto, obrigado pela atenção e paciência em todos os momentos.

Aos docentes do Departamento de Clínica Infantil, Odontologia Preventiva e Social da FORPUSP: Professor Doutor Adilson Thomazinho, Professora Doutora Aldevina Campos de Freitas, Professora Doutora Alexandra Mussolino de Queiroz, Professora Doutora Andiara De Rossi, Professora Doutora Janete Cinira Bregagnolo, Professor Doutor Fábio lourenço Romano, Professor Doutor José Arnaldo Viana Cione, Professor Doutor José Tarcísio de Lima Ferreira, Professora Doutora Kranya Victoria díaz Serrano, Professora Doutora Léa Assed Bezerra da Silva, Professora Doutora Maria Bernadete Sasso Stuani, Professora Doutora Maria da Conceição Pereira Saraiva, Professora Doutora Marlívia Gonçalves de Carvalho Watanabe, Professora Doutora Mírian Aiko Nakane Matsumoto, Professor Doutor Paulo Nelson Filho, Professora Doutora Raquel Assed BezerRa da Silva, Professor Doutor Ricardo Henrique Alves DA Silva, Professora Doutora Sada Assed e Professor Doutor Wilson Mestriner Júnior.

Vocês foram um incentivo em minha vida acadêmica. Obrigado pelas oportunidades a mim concedidas e pelos valiosos conhecimentos transmitidos durante nosso convívio.

Aos alunos do mestrado do Curso de Pós-graduação em Odontopediatria: Camila ScAtenA, Cíntia Guimarães de Almeida, Danielle Torres de Azevedo, Elaine Machado Pingueiro, Fernanda Regina Ribeiro Santos, Iliana ferraz Sabatini, Késsia SuÊnia fidelis de Mesquita, lígia Maria Napolitano Gonçalves, luciane Almeida do Carmo, Marcela Martin del Campo Fierro, Marília Pacífico lucisano, paula dariana fernandes ferreira e Talitha de Siqueira Mellara por me ajudarem sempre, e por proporcionarem uma agradável convivência. Saudades! 
Aos alunos do doutorado do Curso de Pós-graduação em Odontopediatria: CRIStina Bueno Brandão, Giselle de Angelo Souza leite, Kleber Cortes Bonifácio, larissa Moreira Spinola de Castro, leonardo Biscaro Pereira, Marcela Cristina Damião Andrucioli, Marina Fernandes de Sena, Marta estela Saravia, Marta Maria Martins giamatei Contente, Maya Fernanda Manfrin Arnez, Milena Silva Campos, e Walter Raucci Neto pela agradável convivência.

Aos funcionários do Departamento de Clínica Infantil, Odontologia Preventiva e Social e da Clínica de Pacientes Especiais da FORP-USP:

Fátima Aparecida Jacinto Daniel, Michel Cristina leite Ravanholo, filomena lelli Placciti, Benedita Viana Rodrigues, Carmo Eurípedes terra Barreto, José aparecido Neves do Nascimento, Marco antônio dos Santos, Nadir das Dores Gardin Felício, Renata fernandes Rodrigues, Vera Ribeiro do Nascimento, Mariângela de Oliveira e Renata Cristina Rosa.

Obrigada pelo diuturno apoio. Vocês também foram meus mestres durante esta etapa.

Aos funcionários do "Centro de Formação de Recursos Humanos Especializados no Atendimento Odontológico de Pacientes Especiais", Benedita Viana Rodrigues, Fátima Rizóli, Nadir Felício e Renata Aparecida Fernandes Rodrigues, pelo carinho e atenção constante.

Aos secretários da Graduação do Departamento de Clínica Infantil, Odontologia Preventiva e Social Filomena Leli Placitti e Matheus Morelli Zanela pela ajuda essencial.

À PATRícIa MARChI, técnica do Departamento de Odontologia Restauradora da Faculdade de Odontologia de Ribeirão Preto - USP, pela colaboração e atenção durante meu curso de Mestrado e pela disposição na execução da parte experimental deste trabalho.

À CAPES (Coordenação de Aperfeiçoamento de Pessoal de Nível Superior), pela bolsa concedida.

\section{A TODOS QUE, DE ALGUMA FORMA, CONTRIBUÍRAM PARA A CONCRETIZAÇÃO DESTE SONHO, MEUS SINCEROS AGRADECIMENTOS.}




\section{RESUMO}

VALÉRIO, RA. Influência do laser de $\mathrm{CO}_{2}$ e de compostos fluoretados no controle da lesão de cárie em esmalte de dente decíduo desmineralizado - análise in vitro da microdureza subsuperficial. [Mestrado]. Faculdade de Odontologia de Ribeirão Preto, Universidade de São Paulo; 2011.

A irradiação com laser de $\mathrm{CO}_{2}$ e o emprego de compostos fluoretados podem contribuir para que o esmalte do dente decíduo se torne mais resistente a desafios ácidos. Assim, o presente estudo tem por objetivo avaliar in vitro o efeito do laser de $\mathrm{CO}_{2}$ e de compostos fluoretados no controle da progressão de lesões de cárie em esmalte de dentes decíduos por meio da análise de microdureza subsuperficial. Foram utilizados 40 caninos humanos decíduos, dos quais foram obtidos fragmentos de $3 \times 3 \times 2 \mathrm{~mm}$. Estes foram submetidos a desafio cariogênico inicial que consistiu na imersão em solução desmineralizadora por 3 horas e remineralizadora por 21 horas, durante 5 dias. Os fragmentos foram distribuídos aleatoriamente em 4 grupos $(n=10)$ de acordo com o tratamento superficial: $\mathrm{CO}_{2}$ - laser de $\mathrm{CO}_{2}(10,6 \mu \mathrm{m}), \mathrm{VF}$ - verniz fluoretado a 5\%, FFA - flúor fosfato acidulado a 1,23\% e ST - sem tratamento (controle). O laser de $\mathrm{CO}_{2}$ foi aplicado no modo ultra pulso, com potência de 0,5 $\mathrm{W}$, densidade de energia de $0,04 \mathrm{~J} / \mathrm{cm}^{2}$. Nos grupos que receberam tratamento com os fluoretos foi realizada uma aplicação de $0,1 \mathrm{~g}$ durante um minuto. Após o tratamento superficial, foi realizado desafio cariogênico durante 5 dias, seguindo o protocolo anteriormente descrito. Foram realizadas 3 leituras de microdureza subsuperficial Knoop (KHN) a $30 \mu \mathrm{m}$ da superfície. Os dados obtidos foram submetidos a análise de variância (ANOVA) e teste de Duncan com significância de 5\%. Verificou-se que a microdureza subsuperficial do esmalte do dente decíduo obtida após irradiação com laser de $\mathrm{CO}_{2}$ foi semelhante à obtida após a aplicação do FFA, mas estatisticamente diferente dos grupos ST e VF $(p \leq 0,05)$, que obtiveram as menores médias. Conclui-se que o laser de $\mathrm{CO}_{2}$ pode contribuir para o controle da progressão de lesões de cárie em esmalte de dentes decíduos.

Palavras-chave: Lasers de $\mathrm{CO}_{2}$, Dente decíduo, Cárie dentária, Fluoretos tópicos, Desmineralização e Dureza. 


\section{ABSTRACT}

VALÉRIO, RA. Influence of $\mathrm{CO}_{2}$ laser and fluoride compounds in the control of caries lesion on demineralized primary tooth enamel - an in vitro subsurface microhardness analysis. [Mestrado]. Faculdade de Odontologia de Ribeirão Preto, Universidade de São Paulo; 2011.

The $\mathrm{CO}_{2}$ laser irradiation and the employment of fluoride compounds may contribute to the deciduous tooth enamel becoming more resistant to acid challenges. Thus, this study aims to evaluate in vitro the effect of $\mathrm{CO}_{2}$ laser irradiation and fluoride compounds in the control of the progression of carious lesions on enamel of deciduous teeth by subsurface microhardness analysis. A total of 40 deciduous canines were used, of which fragments were obtained $3 \times 3 \times 2 \mathrm{~mm}$. These fragments were submitted to an initial cariogenic challenge that consisted of immersion on demineralizing solution for 3 hours and remineralizing solution for 21 hours, for 5 days. The fragments were randomly divided into 4 groups $(n=10)$ according to the superficial treatment: $\mathrm{CO}_{2}-\mathrm{CO}_{2}$ laser $(10.6 \mu \mathrm{m}), \mathrm{VF}$ - fluoride varnish $5 \%$, FFA - acidulated phosphate fluoride $1.23 \%$ and ST - without treatment (control). The $\mathrm{CO}_{2}$ laser was applied in ultra pulse mode with power of $0.5 \mathrm{~W}$ and power density of $0.04 \mathrm{~J} / \mathrm{cm} 2$. In the groups treated with fluoride application was performed from $0.1 \mathrm{~g}$ for one minute. After superficial treatment, cariogenic challenge was performed during 5 days, following the protocol described previously. Three Knoop subsurface microhardness (KHN) readings were performed at $30 \mu \mathrm{m}$ from the surface. The data obtained were subjected to analysis of variance (ANOVA) and Duncan test with significance of $5 \%$. It was found that the subsurface microhardness on the enamel of deciduos teeth obtained after irradiation with $\mathrm{CO}_{2}$ laser was similar to that obtained after the application of FFA but statistically different from the VF and ST groups ( $p \leq 0.05$ ) that received the lowest average. It was concluded that the $\mathrm{CO}_{2}$ laser can contribute to the control of the progression of carious lesions on enamel of deciduous teeth.

Keywords: $\mathrm{CO}_{2}$ lasers, deciduous teeth, caries, topic fluoride, demineralization and hardness. 


\section{SUMÁRIO}

I NTRODUÇÃO.

PROPOSIÇÃO.

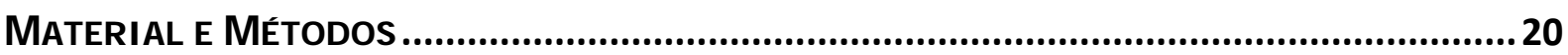

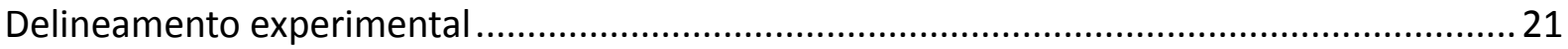

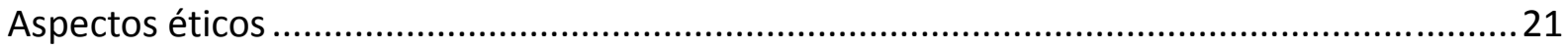

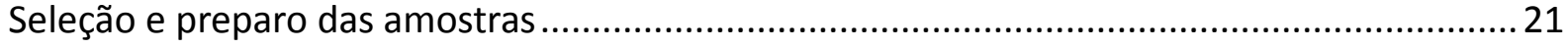

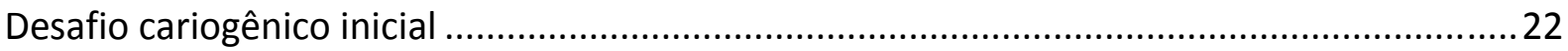

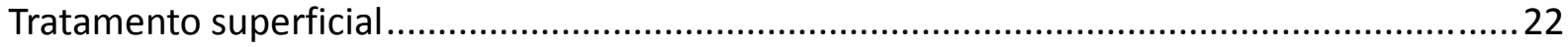

Desafio cariogênico pós-tratamento superficial..................................................................23

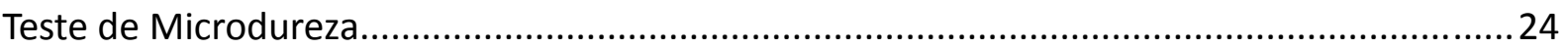

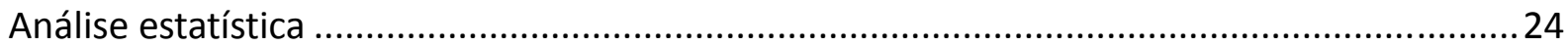

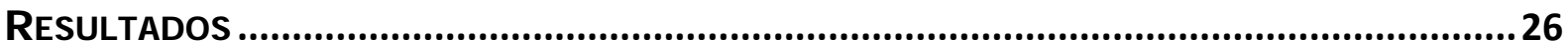

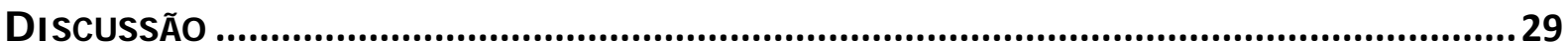

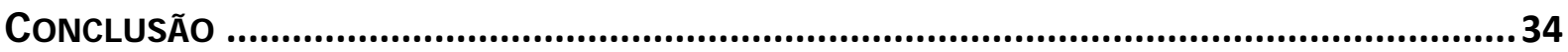

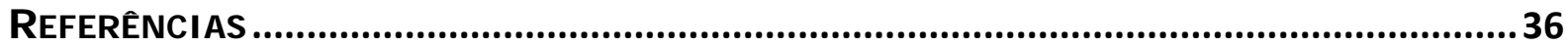

ANEXO 
I NTRODUÇÃO 
Frente aos avanços científicos e tecnológicos nas áreas da Saúde, o modelo odontológico cirúrgico-restaurador vem sendo substituído por conceitos e procedimentos focados na prevenção das doenças e promoção de saúde bucal. Medidas educativas e preventivas colaboram na redução dos índices da doença cárie, juntamente com a evolução dos materiais odontológicos e a implementação de técnicas inovadoras, como a irradiação laser que pode contribuir na prevenção da progressão e instalação da doença cárie, principalmente em crianças e adolescentes.

De acordo com a teoria atômica proposta por Einstein em 1917 e nos estudos pioneiros de Gordon et al. em 1955 e Schawlow e Townes em 1958, o pesquisador norteamericano Theodore Harold Maiman em 1960 idealizou e desenvolveu a primeira fonte de emissão estimulada de luz visível por meio da excitação de um cristal de rubi no interior de uma câmara ou ressonador. Para definir esse sistema de luz foi proposto o termo LASER, acrônimo de Light Amplification by Stimulated Emission of Radiaton - amplificação da luz por emissão estimulada de radiação (Sulewski, 2000).

Os equipamentos de laser produzem uma luz com características específicas. Essa luz é monocromática (possui frequência muito bem definida), coerente (possui relações de fase bem definidas) e colimada (propaga-se como um feixe unidirecional). Sua classificação está vinculada ao meio ativo que pode ser sólido (cristal), líquido (corantes) ou gasoso (HélioNeônio, $\mathrm{CO}_{2}$ ) que determina seu comprimento de onda diferenciando a interação com cada tecido (Coluzzi, 2000).

A interação laser-tecido depende de parâmetros de radiação, como o modo de emissão do feixe (Brugnera Junior \& Pinheiro 1998), distância focal (Chimello et al., 2008), fluxo de água (Colucci et al., 2008), comprimento de onda (Featherstone et al., 1998), densidade de energia (Borsatto et al., 2009), duração e taxa de repetição de pulsos (Gonçalves et al., 2008) e das propriedades dos tecidos biológicos como absorção, reflexão, transmissão e dispersão, bem como das características espaciais, temporais e propriedades ópticas (Gimbel, 2000).

A doença cárie é um processo crônico, de natureza dinâmica, originada pelo desequilíbrio dos fenômenos de desmineralização - remineralização, no qual grande quantidade de mineral é perdida pelos tecidos dentários (Thylstrup et al., 1988). Quando o esmalte é exposto aos ácidos formados durante o metabolismo bacteriano, seus minerais são 
removidos dos cristais de hidroxiapatita, que reduz seu tamanho, e leva a ampliação dos espaços intercristalinos, aumentando a porosidade da superfície dentária.

Dentre os recursos utilizados no controle da desmineralização do esmalte em dentes decíduos tem-se a aplicação de compostos fluoretados, sob diferentes formas de apresentação como gel e verniz (Weintraub et al., 2006; Castellan et al., 2007; Santos et al., 2009) e dentrifício fluoretado (Santos et al., 2009; Hellwig et al., 2010) em diferentes concentrações. O principal efeito dos fluoretos é interferir na dinâmica da doença cárie, reduzindo a desmineralização e aumentando a remineralização do substrato dentário (Tatevossian, 1990). A capacidade do flúor fosfato acidulado em tornar o substrato do dente decíduo mais ácido resistente quando submetidos a desafios cariogênicos foi constatado por Castellan et al. em 2007. Com o objetivo de se obter um contato mais prolongado dos fluoretos com o esmalte dentário foi introduzido o verniz fluoretado (Beltran-Aguilar et al., 2000), que são fáceis de aplicar e seguros (Bawden, 1998). No entanto, para que os fluoretos exerçam um papel efetivo no controle da desmineralização é importante sua presença constante na cavidade bucal (Ogaard, 2001).

A alta atividade da doença cárie em dentes decíduos impulsionou o aperfeiçoamento dos métodos preventivos existentes, bem como a introdução de técnicas inovadoras como a irradiação com o laser de $\mathrm{CO}_{2}$ (Tange et al., 2000; Tagliaferro et al., 2007; da Silva Tagliaferro et al., 2009), a fim de agir como coadjuvantes no controle da doença cárie.

Desenvolvido por Patel et al. em 1964 o laser de $\mathrm{CO}_{2}$ emite luz infravermelha com comprimento de onda de 9.3, 9.6, 10.3 ou $10.6 \mu \mathrm{m}$, fora do espectro visível ao olho humano. Esses comprimentos de onda são mais apropriados para a utilização em esmalte dentário, pois produzem radiação na região do infravermelho que coincide com algumas bandas de absorção da hidroxiapatita, principalmente os grupamentos fosfato e carbonato (Featherstone et al., 1998). Desta forma, maior efetividade na prevenção de cárie pode ser obtida com menor ocorrência de efeitos deletérios aos tecidos dentários (Zuerlein et al., 1999), proporcionando menor dissipação de raios incidentes, com maior rapidez e eficácia do laser. A maior parte da radiação do laser de $\mathrm{CO}_{2}$ é absorvida nos poucos micrometros externos da superfície do esmalte e convertida em calor, causando perda de carbonato do mineral e fusão dos cristais de hidroxiapatita, diminuindo, desta forma, os espaços interprismáticos (Klein et al., 2005; Tsai et al., 2002), além de, aumentar sua resistência 
ácida, reduzir a reatividade do mineral, promovendo assim um efeito cárie preventivo (Rodrigues et al., 2004; da Silva Tagliaferro et al., 2009).

Considerando que o laser de $\mathrm{CO}_{2}$ propicia a criação de uma superfície ácido resistente e frente a escassez de estudos que avaliem a influência do laser de $\mathrm{CO}_{2}$ no esmalte decíduo desmineralizado, faz-se necessário o desenvolvimento de pesquisas in vitro, afim de que esta tecnologia seja aplicada de maneira segura na clínica Odontopediátrica. 
Proposi ÇÃo 
O objetivo do presente estudo foi avaliar in vitro o efeito da irradiação do laser de $\mathrm{CO}_{2}$ e de compostos fluoretados no controle da progressão de lesões de cárie em esmalte de dentes decíduos desmineralizados por meio da análise da microdureza subsuperficial. 


\section{Materi al e Métodos}




\section{Delineamento experimental}

O fator em estudo foi o tratamento superficial em 4 níveis $\left[\mathrm{CO}_{2}\right.$ - laser de $\mathrm{CO}_{2}$ comprimento de onda $10.6 \mu \mathrm{m}$; VF - verniz fluoretado a 5 \%; FFA - flúor fosfato acidulado a 1,23\%; ST - sem tratamento (controle)]. A amostra do experimento foi composta por 40 fragmentos de esmalte humano decíduo que foram distribuídos entre os 4 tratamentos de superfície $(n=10)$, de acordo com um delineamento em blocos completos e casualizados. A variável de resposta quantitativa foi a microdureza subsuperficial (KHN) do substrato submetido ao desafio cariogênico. A figura 1 representa o desenho esquemático da metodologia empregada.

\section{Aspectos éticos}

Foram utilizados caninos humanos decíduos hígidos, previamente obtidos do Banco de Dentes da Faculdade de Odontologia de Ribeirão Preto / USP (processo no 2010.1.1373.58.9) aprovado pelo comitê de ética em pesquisa.

\section{Seleção e preparo das amostras}

Os dentes decíduos foram limpos com curetas periodontais, seguida de profilaxia com pasta de pedra-pomes e água realizada com taça de borracha em baixa rotação (N270, Dabi Atlante, Ribeirão Preto SP, Brasil) e armazenada em solução de timol 0,1\% a $4^{\circ} \mathrm{C}$ (Kwon et al., 2005). A ausência de trincas, hipoplasia e hipomineralização foi comprovada através de lupa estereoscópica com aumento de 20X (Leica, S6 D Stereozoom, Leica Mycrosystems AG, Suíça). Posteriormente, os dentes foram seccionados na junção amelo-cementária em máquina de corte (Isomet 1000; Buehler, Lake Bluff, IL, EUA), refrigerada à água de modo a separar as porções coronárias e radiculares. A face vestibular de cada dente foi seccionada para obter um fragmento de esmalte medindo $3 \times 3 \times 2 \mathrm{~mm}$.

Os fragmentos foram fixados em blocos de resina acrílica utilizando cera fundida (Cera Escultura Prótese Fixa, Asfer Indústria Química Ltda., São Caetano do Sul - SP, Brasil) com as subsuperfícies voltadas para o meio externo. Em seguida, as subsuperfícies foram planificadas em Politriz giratória (DP-9U2; Struers S/A, Copenhagen, Dinamarca) refrigerada à água com lixas d’agua de granulação 1200 (Hermes Abrasives Ltd., VA, EUA) e polidas com pasta de alumina $0.3 \mu \mathrm{m}$ (Arotec S/A Ind. Com., São Paulo, Brasil) em disco de feltro polidor (ATM, Altenkirchen, Alemanha) (Hara et al., 2003). Para que se obtivesse uma amostra de 
fragmentos padronizada, foram realizadas três leituras na lateral dos fragmentos (subsuperfície) distantes $30 \mu \mathrm{m}$ da superfície e a $100 \mu \mathrm{m}$, uma da outra, por meio de um microdurômetro HMV-2000 (Shimadzu Corporation, Kyoto, Japão) (Hara et al., 2003) com penetrador de diamante para dureza Knoop (KHN) e célula de carga de 25 gramas durante 5 segundos (Klein et al., 2005; Rodrigues et al., 2006). A média das 3 medidas foi utilizada como o valor de microdureza inicial do fragmento, sendo que os fragmentos que apresentaram valor médio (20\%) superior ou inferior ao valor da média geral de todos os fragmentos foram descartados (Hara et al., 2006). Quarenta fragmentos de esmalte de dente decíduo foram selecionados baseados nos valores de dureza Knoop iniciais da lateral de seus fragmentos.

\section{Desafio cariogênico inicial}

Com o objetivo de se obterem lesões iniciais microscópicas de mancha branca padronizadas, simulando pacientes com alta atividade da doença cárie, um desafio cariogênico artificial foi realizado em todos os fragmentos. Os espécimes foram reposicionados com a superfície vestibular voltada para o meio externo nos blocos de resina e fixados com cera. Todas as superfícies, exceto a vestibular, foram cobertas com cera fundida e armazenados individualmente em recipientes plásticos. O desafio cariogênico inicial foi realizado durante 5 dias conforme o protocolo proposto por Argenta et al., 2003. Neste modelo, lesões de cárie artificiais foram produzidas pela imersão dos fragmentos em solução desmineralizante ( $\mathrm{pH} 4,6)$, por 3 horas e solução remineralizante $(\mathrm{pH} 7,0)$, por 21 horas à temperatura de $37^{\circ} \mathrm{C}$. Após a indução de lesões artificiais de cárie os espécimes foram mantidos em umidade relativa por 2 dias à temperatura de $4^{\circ} \mathrm{C}$.

\section{Tratamento superficial}

De acordo com o delineamento de blocos completos e casualisados, os espécimes foram divididos de acordo com o tratamento em 4 grupos ( $\mathrm{n}=10$ ): $\mathrm{CO}_{2}$ - laser de $\mathrm{CO}_{2}, \mathrm{VF}$ verniz fluoretado a $5 \%$, FFA - flúor fosfato acidulado a 1,23\%, ST - sem tratamento (controle).

O laser de $\mathrm{CO}_{2} \operatorname{com} \lambda=10.6 \mu \mathrm{m}$ (PC 015-D CO 2 laser system, Shanghai Jue Hua Laser Tech. Development Co., Ltd., Shanghai, China), foi aplicado no modo ultrapulso, com potência de $0,5 \mathrm{~W}$, densidade de energia de $0,04 \mathrm{~J} / \mathrm{cm}^{2}$, duração do pulso de $100 \mu \mathrm{s}$ e intervalo entre os pulsos de 0,001 segundos e diâmetro do feixe de 0,4mm. A distância de 
irradiação foi padronizada por um dispositivo que acopla a caneta do laser mantendo-a fixa numa altura pré-estabelecida de $4 \mathrm{~mm}$ (Tepper et al., 2004), enquanto o conjunto dente/placa de acrílico foi posicionado numa base ajustável que permite sua movimentação sincronizada nos eixos $X Y Z$, ou seja, para direita e esquerda, para frente e para trás e para cima e para baixo. Este aparelho possibilitou a varredura completa e uniforme da superfície dentária pelo feixe laser, durante 20 segundos. Após a irradiação, os espécimes foram mantidos em saliva artificial a $37^{\circ} \mathrm{C}$ por 24 horas. Para o preparo da saliva artificial, os reagentes (213mg de $\mathrm{CaCl} 2 \cdot \mathrm{H} 2 \mathrm{O}, 738 \mathrm{mg}$ de $\mathrm{KH} 2 \mathrm{PO} 4,1.114 \mathrm{mg}$ de $\mathrm{KCl}, 381 \mathrm{mg}$ de $\mathrm{NaCl}, 12 \mathrm{~g}$ de tampão Tris, 2,2g de mucina gástrica, q.s.p. 1 litro) foram pesados em balança analítica (AB204-S/FACT, Mettler Toledo, Columbus, OH, EUA) e submetidos à agitação, ajustando o $\mathrm{pH}$ da solução para 7,0.

Para os fragmentos que receberam o verniz fluoretado (Duraphat; Colgate-Palmolive Ind. Com. Ltda, São Paulo, SP, Brasil, lote 11. 07-02, pH 4,5) foi aplicado 0,1g do produto (Attin et al., 2005), com microbrush (Dentsply Ind. Com. Ltda, Rio de Janeiro, RJ, Brasil), pesado em balança de precisão por um minuto na superfície seca do esmalte. Após 24 horas de armazenamento em saliva artificial a $37^{\circ} \mathrm{C}$, o verniz fluoretado foi removido com auxílio de lâmina de bisturi (Free-Bac, China), simulando a escovação dental.

Nos fragmentos que receberam o flúor fosfato acidulado 1,23\% (DFL Ind. Com. Ltda, Rio de Janeiro, RJ, Brasil, pH 3,6) 0,1 g do produto pesado em balança de precisão foi aplicado por 1 minuto (Villena et al., 2009) na superfície dental também com auxílio de microbrush e, em seguida, o flúor foi removido do esmalte com papel absorvente e os espécimes foram armazenados em saliva artificial a $37^{\circ} \mathrm{C}$. O grupo controle não recebeu tratamento, sendo mantido em saliva artificial a $37^{\circ} \mathrm{C}$ por 24 horas.

\section{Desafio cariogênico pós-tratamento superficial}

Os espécimes foram colocados novamente em recipientes plásticos e todas as superfícies, exceto a superfície tratada, foram cobertas com cera fundida. Foi realizada a ciclagem de pH do mesmo modo descrito anteriormente, por 5 dias, com o objetivo de simular uma condição de alto desafio cariogênico. 


\section{Teste de Microdureza}

Após o período de desafio cariogênico pós-tratamento superficial os espécimes foram seccionados longitudinalmente e, em seguida, os fragmentos foram fixados com cera fundida deixando a parte interna (seccionada) destes expostos, que foram polidos em Politriz. Após o polimento, os fragmentos foram observados em microscópio óptico para verificar a lisura superficial e submetidos à limpeza em ultra-som (Dabi Atlante, Ribeirão Preto, SP, Brasil) por dois minutos para a remoção dos resíduos de polimento. As impressões foram realizadas em uma das hemi-seç̧ões mantendo o longo eixo do diamante do penetrador paralelo à superfície externa do esmalte utilizando carga estática de 25 gramas durante 5 segundos (Castellan et al., 2007). Foram realizadas três medidas no centro do fragmento, com $100 \mu \mathrm{m}$ de distância uma da outra, a $30 \mu \mathrm{m}$ da superfície, utilizando o microdurômetro HMV-2000 (Shimadzu Corporation, Kyoto, Japão).

\section{Análise estatística}

A média dos valores de microdureza subsuperficial Knoop de cada espécime foi analisada e apresentaram distribuição normal e homogeneidade de variância. Sendo assim a Análise de Variância (ANOVA) foi empregada. O teste de Duncan foi usado para averiguar a diferença entre as médias do fator tratamento superficial com o auxílio do programa SPSS 12.0 para Windows (SPSS Inc., Chicago, IL, USA) com nível de significante de 5\%. 


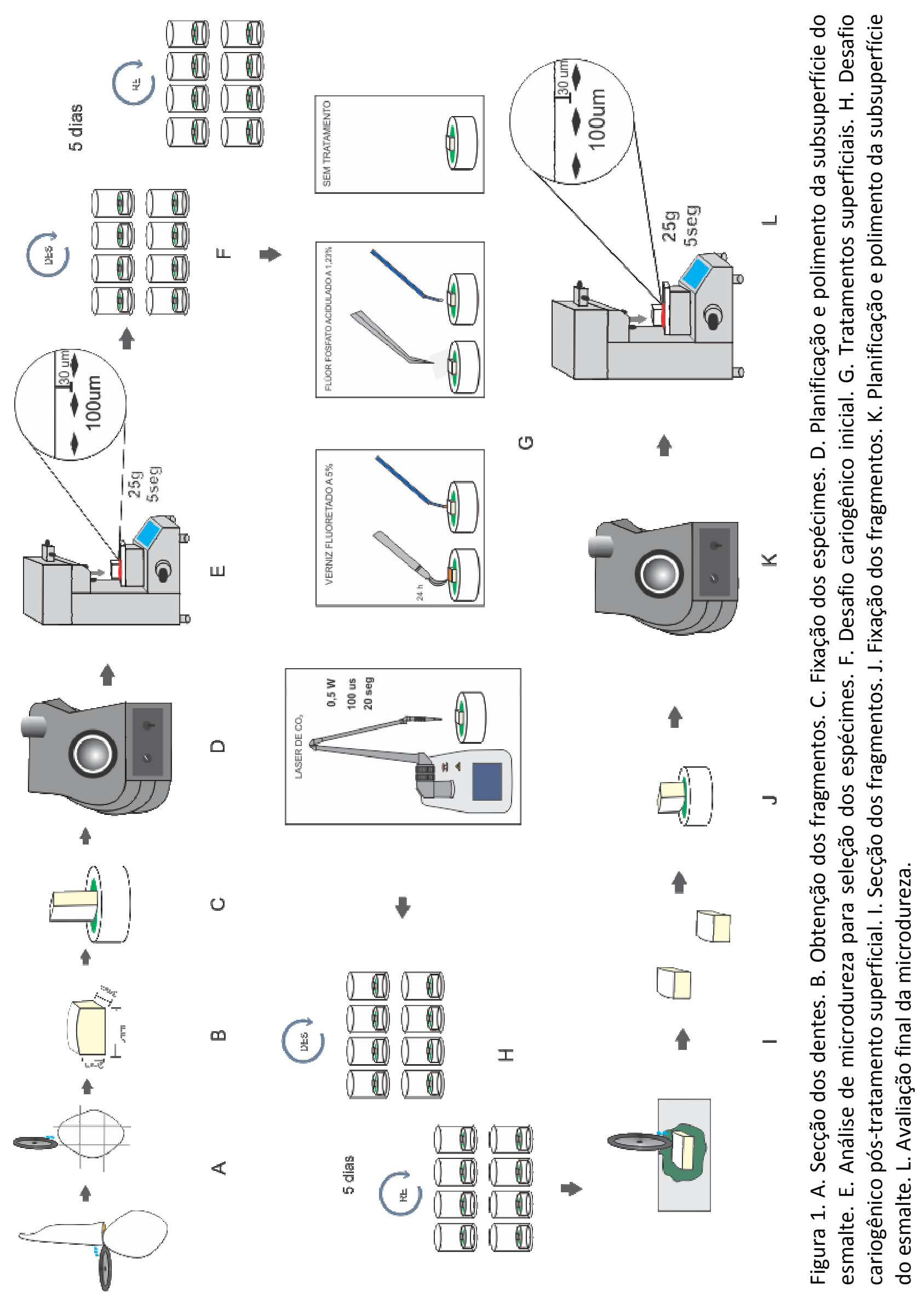


Resultados 
Os resultados de microdureza demostraram que os tratamentos superficiais realizados no esmalte de dentes decíduos foram diferentes estatisticamente entre si $(p \leq 0,05)$, como mostra a tabela 1.

Tabela 1: Média e desvio padrão nos diferentes grupos experimentais

\begin{tabular}{|c|c|c|}
\hline TRATAMENTO & MÉDIA & DESVIO PADRÃO \\
\hline LASER DE $\mathrm{CO}_{2}$ & $324,99 \mathrm{a}$ & 33,78 \\
\hline FLÚOR FOSFATO ACIDULADO a 1,23\% & $309,30 \mathrm{a}$ & 68,42 \\
\hline VERNIZ FLUORETADO a $5 \%$ & $211,66 \mathrm{~b}$ & 54,22 \\
\hline SEM TRATAMENTO (CONTROLE) & 209,86 b & 67,03 \\
\hline
\end{tabular}

Letras iguais indicam similaridade estatística.

O teste de Duncan mostrou que o tratamento superficial com laser de $\mathrm{CO}_{2}$ obteve os maiores valores de microdureza $(\mathrm{KNH})$ em esmalte de dentes decíduos, porém não foi estatisticamente diferente do flúor fosfato acidulado a 1,23\%. Contudo, houve diferença estatisticamente significante com os demais grupos (controle e verniz fluoretado a $5 \%$ ).

Não houve diferença estatisticamente significante entre os grupos sem tratamento (controle) e verniz fluoretado a 5\%. O gráfico 1 representa os valores de microdureza dos tratamentos superficiais. 


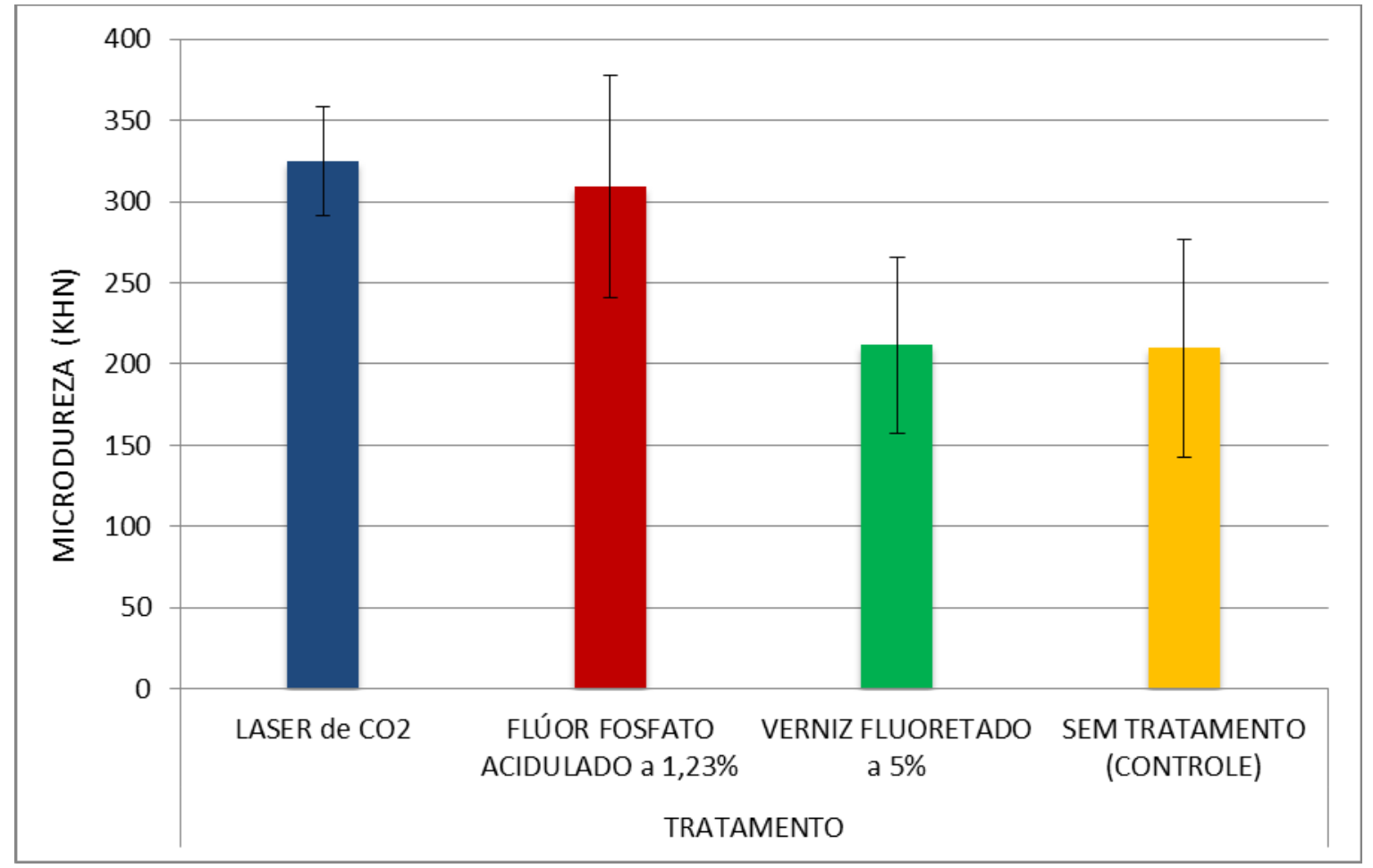

Gráfico 1. Valores de microdureza (média e desvio padrão) de acordo com os tratamentos superficiais 


\section{DI sCUSSÃo}


A cárie dentária pode ser definida como uma doença de natureza infecciosa, que resulta da interação de vários fatores, ocasionando a perda das estruturas dentais mineralizadas e consequente destruição orgânica desses tecidos (Cury, 2001). Esses fatores incluem o uso de uma dieta rica em carboidratos fermentáveis, que servem de substrato para os microrganismos cariogênicos, os quais atuam na superfície dental com maior ou menor intensidade, na dependência da suscetibilidade do hospedeiro (Berkowitz, 2003) e do tempo de interação entre esses fatores.

Compostos fluoretados (Santaella et al., 2004; Jiang et al., 2005; Weintraub et al., 2006; Santos et al., 2009; Hellwig et al., 2010) e o laser de $\mathrm{CO}_{2}$ (da Silva Tagliaferro et al., 2009), tem sido empregados na prevenção e controle de lesões de cárie em dentes decíduos com o intuito de interferir nos processos de des-remineralização. O laser de $\mathrm{CO}_{2}$ é responsável por aumentar a resistência ácida do esmalte irradiado (Rodrigues et al., 2004; da Silva Tagliaferro et al., 2009) e os fluoretos são capazes de se incorporar a esse substrato prevenindo a instalação de lesões cariosas, promovendo menor desmineralização e maior remineralização do esmalte pelo ganho de minerais (Tatevossian, 1990).

O comportamento do Laser de $\mathrm{CO}_{2}$ no esmalte de dentes decíduos e permanentes pode ser distinto devido as diferenças existentes entre esses substratos. O esmalte do dente decíduo, apresenta prismas que se direcionam paralelamente entre si, em uma zona de aproximadamente $30 \mu \mathrm{m}$, denominada camada aprismática (Low et al., 2008), que pode interferir nos processos de desmineralização (Kuhar et al., 1997), sendo mais espessa e uniforme em comparação ao esmalte permanente (Fava et al., 1997). A mineralização dos dentes decíduos é menor em relação aos dentes permanentes, sendo que a porcentagem de cálcio e fosforo é menor nos dentes decíduos (de Menezes Oliveira et al., 2010), a espessura do esmalte decíduo é quase a metade do esmalte do dente permanente (Mortimer, 1970), além de apresentar diferente translucidez, o que pode estar associada à maior porosidade.

A variável de resposta para quantificar a resistência ácida do esmalte decíduo empregada nesse estudo foi a microdureza subsuperficial, a qual permite verificar a perda ou ganho de mineral, após ciclos de des e remineralização (Castellan et al., 2007). Nesse estudo, as medidas foram iniciadas a $30 \mu \mathrm{m}$ da superfície do esmalte decíduo, ou seja, o mais próximo possível da superfície dental, uma vez que medidas iniciadas a $25 \mu \mathrm{m}$ de profundidade não são adequadas (Featherstone \& Zero, 1992; Arends \& ten Bosch, 1992). 
No presente estudo, o tratamento superficial com laser de $\mathrm{CO}_{2}$ obteve os maiores valores de microdureza ( $\mathrm{KNH}$ ) em esmalte de dentes decíduos desmineralizado, mas não foi estatisticamente diferente do flúor fosfato acidulado a 1,23\%. A provável justificativa para o aumento da resistência ácida do esmalte decíduo após tratamento com o laser de $\mathrm{CO}_{2}$, é decorrente do efeito térmico (Fox et al., 1992; Phan et al., 1999). Ao aquecer a superfície dental, o laser de $\mathrm{CO}_{2}$ causa redução no conteúdo de carbonato e desnaturação parcial da matriz do esmalte (Featherstone \& Nelson, 1987; Hsu et al., 2000), o que provoca a diminuição da permeabilidade, dificulta a difusão dos ácidos e, consequentemente, reduz a desmineralização da estrutura (Can et al., 2008; da Silva Tagliaferro et al., 2009; EstevesOliveira et al., 2009).

A redução do conteúdo de carbonato observada em esmalte de dentes permanentes promovida pela irradiação com laser de dióxido de carbono (Kuroda \& Fowler, 1984; Nelson et al., 1987; Phan et al., 1999; Zuerlein et al., 1999) resulta em menor solubilidade da hidroxiapatita (Featherstone, 2000). O aumento do tamanho dos cristais (Kantola et al., 1973; Ferreira et al., 1989; McCormack et al., 1995), o derretimento (Kuroda \& Fowler, 1984; Nelson et al., 1987; Ferreira et al., 1989; Meurman et al., 1992; McCormack et al., 1995; Tsai et al., 2002), a fusão e a recristalização (Kantola et al., 1973) do esmalte irradiado também reduziram a dissolução do esmalte de dentes permanentes frente ao desafio ácido.

$\mathrm{O}$ esmalte dental irradiado com o laser de $\mathrm{CO}_{2}(\lambda=10.6 \mu \mathrm{m})$ apresentou áreas circulares, de fusão, vitrificação, presença de gotículas cristalizadas e sulcos em forma de ondas. Essas alterações podem fundir regiões de má-coalescência do esmalte dentário como cicatrículas e fissuras, diminuindo os nichos disponíveis para o acúmulo de resíduos na superfície oclusal (Brugnera-Júnior e Pinheiro, 1998).

Por outro lado, de acordo com alguns pesquisadores o emprego de densidades de energia entre 0,3 e $12 \mathrm{~J} / \mathrm{cm}^{2}$ com comprimento de onda de $10.6 \mu \mathrm{m}$, em modo pulsado, tem causado pouca ou nenhuma mudança morfológica (Kantorowitz et al., 1998; Hsu et al., 2000). Baseados nesta afirmativa, o derretimento e a fusão da superfície podem não ser necessários para aumentar a resistência ácida do esmalte, como observado por da Silva Tagliaferro et al. em 2009 que não observaram alterações físicas na superfície do esmalte decíduo tratado com laser de $\mathrm{CO}_{2}$.

Tem sido relatado que quando uma solução ou gel contendo alta concentração de fluoreto entra em contato com a superfície dental, ocorre dissolução da camada mais 
externa do esmalte $(0,1$ a $0,2 \mu \mathrm{m})$ e o cálcio dissolvido é reprecipitado na forma de fluoreto de cálcio (Margolis \& Moreno, 1990). Este composto serve como um reservatório de fluoreto para ser liberado durante os desafios cariogênicos (Bruun \& Givskov, 1991; Øgaard, 2001). Adicionalmente, a formação de depósitos minerais enriquecidos com flúor no interior do esmalte poderia bloquear parcialmente o transporte de ácidos no mineral (diminuição da taxa da difusão), um fenômeno que reduziria a formação e/ou a progressão de lesões de cárie (Takagi et al., 2000). Sendo assim estudos comprovaram que aplicações tópicas de flúor fosfato acidulado em dentes decíduos são eficazes no processo de desmineralização e controle de lesões de cárie (Jiang et al., 2005; Castelan et al., 2007; Santos et al., 2009).

A redução do $\mathrm{pH}$ dos agentes fluoretados proporciona aumento da deposição de fluoreto de cálcio durante a aplicação tópica (Rolla et al., 1990). Tenuta et al. em 2008, afirmam que mais importante do que ter fluoreto em altas concentrações no esmalte, é possuir fluoreto disponível na cavidade bucal para ser incorporado à estrutura dental. Assim, quando o mineral solúvel hidroxiapatita for dissolvido como consequência do processo de cárie, podem ser recomendadas aplicações tópicas diárias por grandes períodos, com menor concentração de fluoreto (Mellberg et al., 1967). A aplicação tópica de fluoretos mais ácidos e mais concentrados, poderia oferecer uma maior proteção contra a desmineralização do esmalte dentário (Delbem et al., 2002; Wiegand et al., 2005), com maior incorporação de fluoreto ao esmalte (Villena et al., 2009).

O tempo de aplicação do FFA de um minuto foi estabelecido em função de não haver diferenças significativas na inibição (Delbem et al., 2002) ou na redução da profundidade da lesão de cárie (Garcia-Godoy et al., 1994), bem como na incorporação de flúor ao esmalte (Villena et al., 2009) com tempos de aplicação de um ou quatro minutos.

No presente estudo, não foram encontradas diferenças na microdureza subsuperficial entre os tratamentos realizados com o verniz fluoretado a $5 \%$ e o grupo sem tratamento (controle). Esses resultados podem ser justificados em função do verniz fluoretado a $5 \%$ ter sido aplicado uma única vez, a literatura revela controle da progressão de lesões de cárie em esmalte decíduo por meio de três aplicações em estudos in vivo (Castillo et al., 2004; Weinstein et al., 2009), e in vitro (Seppã, 1988). Outro aspecto a ser observado é que foram realizadas duas etapas de ciclagem de pH (antes e após os tratamentos), simulando um paciente com alto desafio cariogênico com maior risco ao 
desenvolvimento de lesões de cárie, sendo que quanto maior o grau de desmineralização mais difícil é o controle da cárie.

Tem-se também que o $\mathrm{pH}$ do verniz fluoretado a $5 \%(\mathrm{pH}=4,5)$ é maior do que o apresentado pelo FFA a 1,23\% $(\mathrm{pH}=3,6)$ podendo levar a formação de menor quantidade de fluoreto de cálcio, sendo que, cerca de $20 \%$ do fluoreto presente está numa forma solúvel (Hayacibara et al., 2004).

Revisões sistemáticas (Rozier et al., 2001; Marinho et al., 2002) em relação ao efeito preventivo dos vernizes fluoretados na dentição decídua são contraditórias, sendo observado benefício substancial à dentição decídua (Marinho et al., 2002). No entanto Petersson et al. em 2004 e Rozier et al. em 2001, não encontraram evidências conclusivas de que o tratamento com verniz fluoretado reduza a incidência de cárie. A Academia Americana de Odontopediatria 2009/2010 recomenda o uso profissional do verniz fluoretado para prevenir ou reverter a desmineralização do esmalte dentário em crianças com risco moderado ou elevado de desenvolver cárie dentária, sendo que a ação do fluoreto dependente da técnica e frequência de aplicação da substância fluoretada (Mandel, 1996; Clarkson et al., 2000).

Devido as dificuldades relacionadas a modelos de estudo in vivo, no que diz respeito à ética e a complexidade do meio bucal, modelos laboratoriais que simulam o meio bucal in vitro foram desenvolvidos (Argenta et al., 2003; Castellan et al., 2007). Estes modelos consistem na exposição do esmalte de dente decíduo a ciclos combinados de des e remineralização que visam simular as variações dinâmicas de saturação mineral e pH associado com o processo natural do desenvolvimento das lesões de cárie.

$\mathrm{O}$ modelo de ciclos de $\mathrm{pH}$ para avaliar a influência de diferentes tratamentos no controle de lesões de cárie em esmalte humano foi empregado primeiramente por Featherstone et al. em 1986 e modificado para dentes decíduos por Argenta et al. em 2003, onde os espécimes foram submetidos a desafios cariogênicos por 5 dias, sendo as amostras individualmente imersas em solução DES $(\mathrm{pH}=4,6)$ por 3 horas e solução $\operatorname{RE}(\mathrm{pH}=7,0)$ por 21 horas que apresenta um grau de saturação dos minerais semelhante a saliva.

Sendo assim, o laser de $\mathrm{CO}_{2}$ pode ser um recurso adicional contribuindo no controle da progressão de lesões de cárie em esmalte de dentes decíduos e estudos devem ser realizados com o intuito de verificar sua ação em um ambiente que simule as condições clínicas por meio do desenvolvimento de protocolos in situ. 
Conclusão 
Considerando a metodologia utilizada e os resultados obtidos pode-se concluir que:

O laser de $\mathrm{CO}_{2}$ e o flúor fosfato acidulado a 1,23\% proporcionaram maior controle da progressão de lesões de cárie em esmalte decíduo desmineralizado.

A microdureza do esmalte do dente decíduo desmineralizado que recebeu aplicação do verniz fluoretado a $5 \%$, foi semelhante ao grupo que não recebeu tratamento superficial, apresentando as menores médias. 
1. American Academy of Pediatric Dentistry. Policy on use of fluoride. Pediatric Dentistry. Reference manual 2009/2010;31(6):34-35.

2. Arends J, ten Bosch JJ. Demineralization and remineralization evaluation techniques. J Dent Res 1992;71:924-928.

3. Argenta RM, Tabchoury CP, Cury JA. A modified pH-cycling model to evaluate fluoride effect on enamel demineralization. Pesqui Odontol Bras 2003;17(3):241-246.

4. Attin T, Grieme R, Paqué F, Hannig C, Buchalla W, Attin R. Enamel fluoride uptake of a novel water-based fluoride varnish. Archives of Oral Biology 2005;50(3):317-322.

5. Bawden JW. Fluoride varnish: a useful new tool for public health dentistry. J Public Health Dent 1998;58(4):266-269.

6. Beltrán-Aguilar ED, Goldstein JW, Lockwood SA. Fluoride varnishes. A review of their clinical use, cariostatic mechanism, efficacy and safety. J Am Dent Assoc 2000;131(5):589-596.

7. Berkowitz RJ. Acquisition and transmission of mutans streptococci. J Can Dent Assoc 2003;31:153-158.

8. Borsatto MC, Torres CP, Chinelatti MA, Pécora JD, Corona SA, Palma-Dibb RG. Effect of Er:YAG laser parameters on ablation capacity and morphology of primary enamel. Photomed Laser Surg 2009;27:253-260.

9. Brugnera Jr A, Pinheiro AL. Laser na odontologia moderna. São Paulo: Pancast; 1998.

10. Bruun $\mathrm{C}$, Givskov H. Formation of $\mathrm{CaF}_{2}$ on sound enamel and in caries-like enamel lesions after different forms of fluoride applications in vitro. Caries Res 1991;25(2):96-100.

11. Can AM, Darling CL, Ho C, Fried D. Non-destructive assessment of inhibition of demineralization in dental enamel irradiated by $\mathrm{CO}_{2}$ laser at ablative irradiation intensities with PS-OCT. Lasers in Surgery and Medicine 2008;40(5):342-349.

12. Castellan CS, Luiz AC, Bezinelli LM, Lopes RM, Mendes FM, De P Eduardo C, De Freitas PM. In vitro evaluation of enamel demineralization after Er:YAG and Nd:YAG laser irradiation on primary teeth. Photomed Laser Surg 2007;25(2):85-90.

13. Castillo JL, Milgrom P. Fluoride release from varnishes in two in vitro protocols. J Am Dent Assoc 2004;135(12):1696-1699.

14. Chimello DT, Serra MC, Rodrigues-Júnior Al, Pécora JD, Corona SA. Influence of Er:YAG laser on microhardness of enamel adjacent to restorations submitted to cariogenic challenge in situ. Photomed Laser Surg 2008;26(4):379-385. 
15. Clarkson JJ, McLoughlin J. Role of fluoride in oral health promotion. Int Dent J 2000;50(3):119-128.

16. Colucci V, Lucisano MP, do Amaral FL, Pécora JD, Palma-Dibb RG, Corona SA. Influence of water flow rate on shear bond strength of resin composite to Er:YAG cavity preparation. Am J Dent 2008;21:124-128.

17. Coluzzi DJ. An overview of laser wavelengths used in dentistry. Dent Clin North Am 2000;44:753-765.

18. Cury JA. Uso do flúor e controle da cárie como doença. In: Baratieri, LN et al. Odontologia restauradora - Fundamentos e possibilidades. São Paulo: Editora Santos; 2001.

19. da Silva Tagliaferro EP, Rodrigues LK, Soares LE, Martin AA, Nobre-dos-Santos M. Physical and compositional changes on demineralized primary enamel induced by $\mathrm{CO}_{2}$ Laser. Photomed Laser Surg 2009;27(4):585-590.

20. De Menezes Oliveira MAH, Torres CP, Gomes-Silva JM, Chinelatti MA, De Menezes FCH, Palma-Dibb RG, Borsatto MC. Microstructure and Mineral Composition of Dental Enamel of Permanent and Deciduous Teeth. Microscopy Research and Technique 2010;73:572577.

21. Delbem AC, Cury JA. Effect of application time of APF and NaF gels on microhardness and fluoride uptake of in vitro enamel caries. Am J Dent 2002;15(3):169-172

22. Einstein A. Zur quantum theorie der strhkung (On the quantum theory of radiation). Phisics Zeitung 1917;18:121.

23. Esteves-Oliveira M, Zezell DM, Meister J, Franzen R, Stanzel S, Lampert F, Eduardo CP, Apel C. $\mathrm{CO}_{2}$ laser $(10.6 \mu \mathrm{m})$ parameters for caries prevention in dental enamel. Caries Research 2009;43(4):261-268.

24. Fava M, Watanabe I, Moraes FF, Costa LRRS. Prismless enamel in human non erupted deciduous molar teeth: A scanning electron microscopic study. Rev Odontol Univ São Paulo 1997;11:239-243.

25. Featherstone JD, Barrett-Vespone NA, Fried D, Kantorowitz Z, Seka W. $\mathrm{CO}_{2}$ laser inhibitor of artificial caries-like lesion progression in dental enamel. J Dent Res 1998;77(6):13971403.

26. Featherstone JD, Nelson DG. Laser effects on dental hard tissues. Advances in Dental Research 1987;1(1):21-26.

27. Featherstone JD, Zero DT. An in situ model for simultaneous assessment of inhibition of demineralization and enhancement of remineralization. J Dent Res 1992;71:804-810. 
28. Featherstone JD. Caries detection and prevention with laser energy. Dent Clin North Am 2000;44(4):955-969.

29. Featherstone JDB, O'really MM, Shariaty M. Enhancement of remineralization in vitro and in vivo. In: Leach AS, editor. Factors relating to demineralization and remineralization of teeth. IRL: Oxford 1986;23-34.

30. Ferreira JM, Palamara J, Phakey PP, Rachinger WA, Orams HJ. Effects of continuous-wave $\mathrm{CO}_{2}$ laser on the ultrastructure of human dental enamel. Arch Oral Biol 1989;34(7):551562.

31. Fox JL, Yu D, Otsuka M, Higuchi WI, Wong J, Powell GL. Initial dissolution rate studies on dental enamel after $\mathrm{CO}_{2}$ laser irradiation. Journal of Dental Research 1992;71(7):13891398.

32. Garcia-Godoy F, Hicks MJ, Flaitz CM, Berg J. Acidulated phosphate fluoride treatment and formation of caries-like lesions in enamel: effect of application time. Pediatr Dent 1994;16(2):158.

33. Gimbel CB. Hard tissue laser procedures. Dent Clin North Am 2000;44:931-953.

34. Gonçalves M, Corona SA, Palma-Dibb RG, Pécora JD. Influence of pulse repetition rate of Er:YAG laser and dentin depth on tensile bond strength of dentin-resin interface. J Biomed Mater Res A 2008;86(2):477-482.

35. Gordon JP, Zeiger HJ, Townes CH. Maser - new type of microwave amplifer, frequency standard, and spectrometer. Phys Rev 1955;99:1264-1274.

36. Hara AT, Queiroz CS, Paes Leme AF, Serra MC, Cury JA. Caries progression and inhibition in human and bovine root dentine in situ. Caries Research 2003;37(5):339-344.

37. Hara AT, Turssi CP, Ando M, González-Cabezas C, Zero DT, Rodrigues AL Jr, Serra MC, Cury JA. Influence of Fluoride-Releasing Restorative Material on Root Dentine Secondary Caries in situ. Caries Research 2006;40(5):435-439.

38. Hayacibara MF, Paes Leme AF, Lima YBO, Gonçalves NCLAV, Queiroz CS, Gomes MJ, Kozlowski FC. Alkali-soluble fluoride deposition on enamel after professional application of topical fluoride in vitro. J Appl Oral Sci 2004;12(1):18-21.

39. Hellwig $E$, Altenburger $M$, Attin $T$, Lussi A, Buchalla W. Remineralization of initial carious lesions in deciduous enamel after application of dentifrices of different fluoride concentrations. Clin Oral Investig 2010;14(3):265-269.

40. Hsu CY, Jordan TH, Dederich DN, Wefel JS. Effects of low-energy $\mathrm{CO}_{2}$ laser irradiation and the organic matrix on inhibition of enamel demineralization. Journal of Dental Research 2000;79(9):1725-1730. 
41. Jiang $H$, Bian Z, Tai BJ, Du MQ, Peng B. The effect of a bi-annual professional application of APF foam on dental caries increment in primary teeth: 24-month clinical trial. J Dent Res 2005;84(3):265-268.

42. Kantola S, Laine E, Tarna T. Laser-induced effects on tooth structure. VI. X-ray diffraction study of dental enamel exposed to a $\mathrm{CO}_{2}$ laser. Acta Odontol Scand 1973;31(6):369-379.

43. Kantorowitz Z, Featherstone JD, Fried D. Caries prevention by $\mathrm{CO}_{2}$ laser treatment: dependency on the number of pulses used. J Am Dent Assoc 1998;129(5):585-591.

44. Klein AL, Rodrigues LK, Eduardo CP, Nobre dos Santos M, Cury JA. Caries inhibition around composite restorations by pulsed carbon dioxide laser application. Eur J Oral Sci 2005;113(3):239-244.

45. Kuhar M, Cevc P, Schara M, Funduk N. Enhanced permeability of acid etched or ground dental enamel. J Prosthet Dent 1997;77:578-582.

46. Kuroda S, Fowler BO. Compositional, structural, and phase changes in in vitro laserirradiated human tooth enamel. Calcif Tissue Int 1984;36(4):361-369.

47. Kwon YH, Lee JS, Choi YH, Lee JM, Song KB. Change of enamel after Er:YAG and $\mathrm{CO}_{2}$ laser irradiation and fluoride treatment. Photomed Laser Surg 2005;23(4):389-394.

48. Low IM, Duraman N, Mahmood U. Mapping the structure, composition and mechanical properties of human teeth. Mater Sci Eng C 2008;28:243-247.

49. Maiman TH. Stimulated optical radiation in ruby. Nature 1960;187:493-494.

50. Mandel ID. Caries prevention: current strategies, new directions. Journal of American Dental Association 1996;127(10):1477-1488.

51. Margolis HC, Moreno EC. Physicochemical perspectives on the cariostatic mechanisms of systemic and topical fluorides. J Dent Res 1990;69:606-613.

52. Marinho VC, Higgins JP, Logan S, Sheiham A. Fluoride varnishes for preventing dental caries in children and adolescents. Cochrane Database Syst Rev 2002;(3):CD002279.

53. McCormack SM, Fried D, Featherstone JD, Glena RE, Seka W. Scanning electron microscope observations of $\mathrm{CO}_{2}$ laser effects on dental enamel. J Dent Res 1995;74(10):1702-1708.

54. Mellberg JR, Englander HR, Nicholson CR. Acquisition of fluoride in vivo by deciduous enamel from daily topical sodium fluoride applications over 21 months. Arch Oral Biol 1967;12(10):1139-1148.

55. Meurman JH, Voegel JC, Rauhamaa-Mäkinen R, Gasser P, Thomann JM, Hemmerle J, Luomanen M, Paunio I, Frank RM. Effects of carbon dioxide, Nd:YAG and carbon dioxide- 
$\mathrm{Nd}$ :YAG combination lasers at high energy densities on synthetic hydroxyaptite. Caries Res 1992;26(2):77-83.

56. Mortimer KV. The relationship of deciduous enamel structure of dental disease. Caries Res 1970;4:206-223.

57. Nelson DG, Wefel JS, Jongebloed WL, Featherstone JD. Morphology, histology and crystallography of human dental enamel treated with pulsed low-energy infrared laser radiation. Caries Res 1987;21(5):411-426.

58. Øgaard B. $\mathrm{CaF}_{2}$ formation: cariostatic properties and factors of enhancing the effect. Caries Res 2001;35(1):40-44.

59. Patel CKN, McFarlane RA and Faust WL. Selective excitation through vibrational energy transfer and optical maser action in $\mathrm{N}_{2}-\mathrm{CO}_{2}$. Physiol Rev 1964;13:617-619.

60. Petersson LG, Twetman S, Dahlgren H, Norlund A, Holm AK, Nordenram G, Lagerlöf F, Söder B, Källestål C, Mejàre I, Axelsson S, Lingström P. Professional fluoride varnish treatment for caries control: a systematic review of clinical trials. Acta Odontol Scand 2004;62(3):170-176.

61. Phan ND, Fried D, Featherstone JDB. Laser-induced transformation of carbonated apatite to fluorapatite on bovine enamel. Lasers in Dentistry V 1999;3593:233-240.

62. Rodrigues LK, Nobre dos Santos M, Featherstone JD. In situ mineral loss inhibition by $\mathrm{CO}_{2}$ laser and fluoride. Journal of Dental Research 2006;85(7)617-621.

63. Rodrigues LK, Nobre dos Santos M, Pereira D, Assaf AV, Pardi V. Carbon dioxide laser in dental caries prevention. J Dent 2004;32(7):531-540.

64. Rølla G, Saxegaard E. Critical evaluation of the composition and use of topical fluorides, with emphasis on the role of calcium fluoride in caries inhibition. J Dent Res 1990;69:780-785.

65. Rozier RG. Effectiveness of methods used by dental professionals for the primary prevention of dental caries. J Dent Educ 2001;65(10):1063-1072.

66. Santaella MR, Braun A, Matson E, Frentzen M. Effect of diode laser and fluoride varnish on initial surface demineralization of primary dentition enamel: an in vitro study. Int J Paediatr Dent 2004;14(3):199-203.

67. Santos L de M, Reis JI, Medeiros MP, Ramos SM, Araújo JM. In vitro evaluation of fluoride products in the development of carious lesions in deciduous teeth. Braz Oral Res 2009;23(3):296-301.

68. Schawlow AL, Townes CH. Infrared and optical lasers. Phys Rev 1958;112:1940. 
69. Seppä L. Effects of a sodium fluoride solution and a varnish with different fluoride concentrations on enamel remineralization in vitro. Scand J Dent Res 1988;96(4):304-309.

70. Sulewski JG. Historical survey of laser dentistry. Dent Clin North Am 2000;44:717-752.

71. Tagliaferro EP, Rodrigues LK, Nobre Dos Santos M, Soares LE, Martin AA. Combined effects of carbon dioxide laser and fluoride on demineralized primary enamel: an in vitro study. Caries Res 2007;41(1):74-76.

72. Takagi S, Liao H, Chow LC. Effect of tooth-bound fluoride on enamel demineralization/ remineralization in vitro. Caries Res 2000;34(4):281-288.

73. Tange $\mathrm{T}$, Fried $\mathrm{D}$, and Featherstone JDB. TEA- $\mathrm{CO}_{2}$ laser inhibition of artificial caries-like lesion progression in primary and permanent tooth enamel. Lasers in Dentistry VI 2000;3910:306-313.

74. Tatevossian A. Fluoride in dental plaque and its effects. J Dent Res 1990;69:645-652.

75. Tenuta LM, Cerezetti RV, Del Bel Cury AA, Tabchoury CP, Cury JA. Fluoride release from $\mathrm{CaF}_{2}$ and enamel demineralization. J Dent Res 2008;87(11):1032-1036.

76. Tepper SA, Zehnder M, Pajarola GF, Schmidlin PR. Increased fluoride uptake and acid resistance by $\mathrm{CO}_{2}$ laser-irradiation through topically applied fluoride on human enamel in vitro. Journal of Dentistry 2004;32(8):635-641.

77. Thylstrup A, Fejerskov O. Tratado de cariologia. Rio de Janeiro: Cultura Médica, 1988.

78. Tsai $\mathrm{CL}$, Lin $\mathrm{YT}$, Huang $\mathrm{ST}$, Chang $\mathrm{HW}$. In vitro acid resistance of $\mathrm{CO}_{2}$ and Nd-YAG lasertreated human tooth enamel. Caries Res 2002;36(6):423-429.

79. Villena RS, Tenuta LM, Cury JA. Effect of APF gel application time on enamel demineralization and fluoride uptake in situ. Brazilian Dental Journal 2009;20(1):37-41.

80. Weinstein P, Spiekerman C, Milgrom P. Randomized equivalence trial of intensive and semiannual applications of fluoride varnish in the primary dentition. Caries Res 2009;43(6):484-490.

81. Weintraub JA, Ramos-Gomez F, Jue B, Shain S, Hoover Cl, Featherstone JD, Gansky SA. Fluoride varnish efficacy in preventing early childhood caries. J Dent Res 2006;85(2):172-176.

82. Wiegand A, Krieger C, Attin R, Hellwig E, Attin T. Fluoride uptake and resistance to further demineralisation of demineralised enamel after application of differently concentrated acidulated sodium fluoride gels. Clin Oral Investig 2005;9(1):52-57.

83. Zuerlein MJ, Fried D, Featherstone JD. Modeling the modification depth of carbon dioxide laser-treated dental enamel. Lasers Surg Med 1999;25(4):335-347. 
ANEXo 


\section{Parecer do Comitê de Ética em Pesquisa}

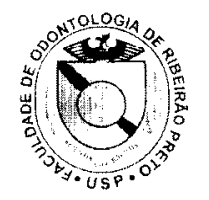

Of. CEP / 486 / FORP

\section{UNIVERSIDAUE DE SÃO PAULO}

Faculdade de Odontologia de Ribeirão Preto Comitê de Ética em Pesquisa

Senhor Pesquisador:

Informamos que o Comitê de Ética em Pesquisa, em sua $115^{a}$ sessão, realizada em 25/11/2010, aprovou o desenvolvimento do projeto de pesquisa envolvendo seres humanos, intitulado "Efeito da irradiaçăo do laser de $\mathrm{CO} 2$ e de compostos fluoretados na inibição da progressão de lesões de cárie em dentes decíduos".

$\mathrm{Na}$ oportunidade, lembramos da necessidade de ser entregue, na secretaria do CEP, o Relatório Final em 25/03/2011, com o respectivo formulário preenchido pelo pesquisador responsável.

Lembramos ainda que, quando da submissão do relatório a este Comitê, quaisquer inclusర̃es ou modificações no projeto original deverão ser comunicadas e justificadas ao CEP, através do formulário supracitado.

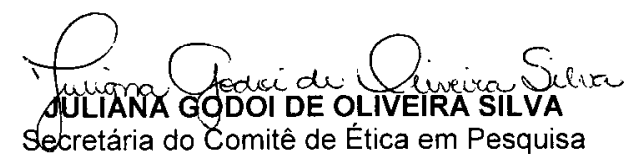

IImo. Sr.

PG. RODRIGO ALEXANDRE VALÉRIO (Profa. Dra. Silmara Aparecida Milori Corona) Departamento de Odontologia Restauradora desta Faculdade 